\title{
ANALISIS KEBIJAKAN STOCK OPNAME DI DINAS KEARSIPAN DAN PERPUSTAKAAN KABUPATEN KUBU RAYA
}

\author{
Fitri Widiyasari, Atiqa Nur Latifa Hanum \\ Program Studi Diploma 3 Perpustakaan FKIP Untan Pontianak \\ Email:fitriwidiyasari@untan.com
}

\begin{abstract}
This study discusses thepolicy stock opname at the Archives and Library Office of Kubu Raya Regency. The purpose of the study was to describe the implementation of thepolicy stock opname at the Archives and Library Office of Kubu Raya Regency as well as the obstacles it faced. This study uses a descriptive method with a qualitative approach. Collecting data by means of observation, documentation and interviews. Informants in this study are Head of Service, Head of Libraries and Librarians. The result of this research is that the Office of Archives and Library of Kubu Raya Regency does not have apolicy stock opname. However, the implementation of the stock taking carried out in 2020 is the implementation of the activities of the Regency/City SNP and is the librarian's idea as the use of free time due to closing services during the covid-19 pandemic. The initial obstacle faced was the lack of understanding of SNP by library human resources. So that no other library human resources are willing to work on it. Constraints in its implementation are the lack of library human resources, no funds, inconsistent implementation time, and lack of attention to the importance of stock taking.
\end{abstract}

Keywords: Library Policy, District/City Library, Stock Opname.

\section{PENDAHULAN}

\begin{tabular}{|c|}
\hline $\begin{array}{l}\text { Menurut Saleh } \\
\text { perpustakaan umum }(2011) \\
\text { perpustakaan yang didirikan oleh } \\
\text { masyarakat umum dan dibiayai oleh } \\
\text { masyarakat itu sendiri baik secara } \\
\text { langsung maupun tidak langsung } \\
\text { misalnyamelalui pajak. Perpustakaan } \\
\text { umum merupakan lembaga yang } \\
\text { dibentuk guna untuk memberikan } \\
\text { layanan kepada masyarakat secara } \\
\text { umum, dengan tidak membedakan dari } \\
\text { berbagai suku, ras, pendidikan, } \\
\text { pekerjaan, usia, jenis kelamin dan lain } \\
\text { sebagainya. Selain itu, perpustakaan } \\
\text { umum juga memiliki ciri-ciri lainnya } \\
\text { seperti: a) bersifat terbuka untuk umum, } \\
\text { b) Tidak ada batasan siapa yang } \\
\text { diperbolehkan masuk, dan c) } \\
\text { pembiayaan oleh masyarakat (Saleh }\end{array}$ \\
\hline
\end{tabular}

dan Komalasari, 2011). Perpustakaan umum Kabupaten/Kota merupakan perpustakaan umum yang berada dilingkungan masyarakat agar dapat membantu dalam mencari informasi. Perpustakaan umum Kabupaten/Kota menyediakan berbagai macam informasi yang dapat membantu masyarakat untuk memenuhi kebutuhan informasi yang dicari.

Prinsip tugas perpustakaan umum Kabupaten/Kota merpakan penyediaan layanan berupa informasi demi kepentingan masyarakat, baik masyarakat ilmiah maupun masyarakat luas yang ada disekelilingnya (Rodin, 2018).

Koleksi bahan pustaka yang dimiliki sebuah perpustakaan harus terus dirawat agar dapat dilayankan dalam 
kondisi yang baik. Salah satu upaya untuk merawat koleksi bahan pustaka adalah dengan cara melakukan kegiatan stock opname. Stock opname merupakan kegiatan mendata ulang koleksi bahan pustaka, mengecek kondisi bahan pustaka, serta untuk mengetahui apakah ada koleksi yang hilang atau rusak. Stock opname idealnya dilakukan sesuai dengan kebijakan dari Standar Nasional Perpustakaan.

Dalam Peraturan Kepala Perpustakaan Nasional Republik Indonesia Nomor 8 tahun 2017 tentang Standar Nasional Perpustakaan Kabupaten/Kota menyebutkan bahwa kegiatan cacah ulang (stock opname) dan penyiangan koleksi minimal dilakukan satu kali dalam tiga tahun atau lebih baiknya satu tahun sekali. Oleh sebab itu, perpustakaan umum wajib melakukan stock opname untuk meminimalisir adanya kehilangan dan kerusakan koleksi. Sama halnya dengan pernyataaan Yulia dan Sujana (2011) dalam buku pengembangan koleksi yang mana biasanya stock opname membutuhkan waktu yang relatif lama sehingga bagi perpustakaan yang kecil biasa dikerjakan setahun sekali dan untuk perpustakaan yang besar minimal 2 sampai 3 tahun sekali.

Apabila merujuk pada Standar Nasional Perpustakaan maka perpustakaan Daerah Kabupaten Kubu Raya belum memenuhi standar stock opname yang telah ditetapkan dalam Standar Nasional Perpustakaan. Sejak berdirinya perpustakaan tepatnya pada tahun 2008 hingga saat ini Dinas Kearsipan dan Perpustakaan Kabupaten Kubu Raya baru melaksanakan stock opname untuk pertama kalinya. Hal ini membuat pelaksanaan stock opname berlangsung sangat lama, karena banyaknya koleksi yang harus didata dan di cek dengan teliti.

Sebagai perpustakaan umum daerah yang wajib memberikan layanan kepada masyarakat, dan penyelenggaraannya harus sesuai dengan kebijakan dan Standar Nasional Perpustakaan Kabupaten/Kota, maka perpustakaan umum daerah Kabupaten Kubu Raya juga melakukan kegiatan stock opname untuk mengetahui kondisi koleksi bahan pustakanya agar dapat memberikan layanan terbaik bagi masyarakat khususnya di kabupaten Kubu Raya.

Dari pemaparan diatas, maka dapat diketahui penelitian ini bertujuan untuk memaparkan tentang penerapan kebijakan stock opname yang dilakukan di Dinas Kearsipan dan Perpustakaaan Kabupaten Kubu Raya serta kendala yang dihadapinya.

\section{METODE PENELITIAN}

Pada penelitian

ini dilakukan menggunakan metode kualitatif dengan pendekatan deskriptif. Data dikumpulkan melalui kegiatan wawancara, observasi dan studi dokumentasi. Peneliti menggunakan tiga aktivitas atau komponen dalam analisis data yaitu reduksi data, penyajian data dan verifikasi data.

a. Reduksi data

Reduksi data memiliki arti memilih, memilah dan merangkum hal-hal yang bersifat pokok, lebih fokus kepada hal penting, serta pencarian tema dan pola yang digunakan (Sugiyono, 2018).

b. Penyajian data

Komponen kedua digunakan untuk mempermudah dalam memahami kejadian yang terjadi, kemudian merancang untuk langkah berikutnya berdasarkan hal yang telah dipahami dan didapatkan. Dalam penelitian kualitatif, data disajikan berupa pemaparan yang singkat, bagan, flowchart, dan hubungan antar kategori (Sugiyono, 2019). Penyajian data yang peneliti sajikan yaitu hasil dari analisis Dinas Kearsipan dan 
Perpustakaan Kubu Raya
dalam Kebijakan stock opname.
c. Verifikasi data
Verifikasi dilakukan untuk mengetahui apakah hasil akhir telah menjawab dari rumusan masalah yang dibuat peneliti sebelum melakukan penelitian. Narasumber pada penelitian ini merupakan orang-orang pilihan peneliti yang dianggap terbaik dalam memberikan informasi yang dibutuhkan oleh peneliti. Adapun informan tersebut adalah Kepala Dinas dan Kepala Bidang Perpustakaan selaku pihak yang mengetahui kebijakan apa yang ditetapkan pada Dinas, mulai dari pembentukan, persetujuan, pengesahan, dan lain sebagainya. Sedangkan Pustakawan dapat memberikan penjelasan mengenai implementsi kebijakan di lapangan dan alasan apabila kebijakan tersebut tidak terlaksana.

Media yang digunakan untuk membantu mempermudah pada penelitian berupa alat tulis dan handphone.

Analisis data dalam penelitian ini menggunakan analisis data deskriptif. Maksud dari data deskriptif yaitu data diambil lebih berfokus dalam bentuk kata-kata atau gambar dibandingkan dengan angka (Emzir, 2012).

\section{HASIL PENELITIAN DAN PEMBAHASAN}

\section{Hasil}

Pelaksanaan kegiatan stock opname di perpustakaan dilakukan untuk mengetahui kebenaran aset koleksi yang dimiliki perpustakaan. Dengan dilaksanakan kegiatan stock opname maka akan didapat beberapa informasi mengenai jumlah koleksi, keadaan fisik buku, daftar serta jumlah judul koleksi, jumlah eksemplar koleksi, koleksi dipinjam, koleksi yang diminati atau tidak minati pemustaka, dan lain sebagainya. Berdasarkan hasil laporan dari kegiatan stock opname dapat dijadikan sebagai bahan pertimbangan untuk melakukan pengembangan koleksi yang dapat menyesuaikan dengan kebutuhan pemustaka. Dilihat dari kebermanfaatan kegiatan stock opname, maka sebaiknya perpustakaan melakukan kegiatan stock opname.

Untuk memudahkan pencarian hasil penelitian, peneliti juga menggunakan dua penelitian terdahulu yang membahas kegiatan Stock opname. Penelitian pertama Dimas Andika Putra yang berjudul "Implementasi Stock opname di perpustakaan UIN Malang" tahun 2015 dengan hasil penelitian kegiatan Stock opname dilakukan satu tahun sekali tepatnya setiap awal tahun. SOP Stock opname dimulai dari kegiatan persiapan, pelaksanaan dan pelaporan.

Penelitian kedua dilakukan oleh Ilham Subagio pada tahun 2019 dengan judul "Stock opname koleksi perpustakaan SDN 34 Pontianak Kota". Hasil dari penelitian berupa penggunaan metode daftar/registrasi yang berisi nomor induk untuk melakukan kegiatan Stock opname. Selain itu, dapat diketahui keuntungan kegiatan Stock opname yang mempermudah dalam mengetahui dokumen yang hilang.

Sedangkan hasil dari penelitian ini kegiatan stock opname berlangsung selama 6 bulan lamanya, dimulai sejak November 2020 sampai dengan Mei 2021. Sumber daya manusia yang melaksanakan kegiatan stock opname yaitu satu pustakawan, satu staf pelayanan perpustakaan, dua siswa magang dari Sekolah Menengah Kejuruan, dan dua mahasiswa magang dari Universitas.

Data aset koleksi yang ada di perpustakaan yaitu meliputi, koleksi tahun pengadaan dimulai dari tahun 2008 hingga tahun 2020, jumlah judul koleksi 7.534judul, jumlah eksemplar 
28.177 koleksi. Koleksi yang ada keseluruhannya dalam kondisi baik. Adapun koleksiyang sering diminati pemustaka adalah koleksi dengan nomor klasifikasi 297 (agama Islam), 600 (ilmu terapan/teknologi), 800 (kesusastraan), 900 (sejarah dan geografi), dan koleksi anak, sedangkan sisanya adalah koleksi yang kurang diminati oleh pemustaka.

\section{Pembahasan}

Menurut KBBI kebijakan berarti seperangkat konsep dan asas yang menjadi garis besar serta dasar rencana dalam melakukan suatu pekerjaan, kepemimpinan dan cara bertindak (tentang pemerintahan, organisasi, dan sebagainya). Dinas Kearsipan dan Perpustakaan Kubu Raya tidak memiliki kebijakan stock opname baik lisan maupun tulisan yang dibuat oleh kedinasan itu sendiri. Oleh sebab itu, kegiatan stock opname yang dilakukan hanya berdasarkan dari Standar Nasional Perpustakaan

Kabupaten/Kota, karena kurang diperhatikannya kegiatan stock opname maka dalam pelaksanaannya masih belum berjalan dengan maksimal.

Kegiatan stock opname idealnya dilakukan satu tahun sekali atau minimal sekali dalam tiga tahun. Sedangkan Perpustakaan Kubu Raya, belum pernah melakukan kegiatan stock opname selama berdirinya perpustakaan yaitu sejak tahun 2008. Stock opname baru dilakukan pertama kalinya pada tahun 2020, yang merupakan ide yang diajukan oleh pustakawan dan staf perpustakaan. Faktor pendorong dilakukan kegiatan stock opname pada tahun 2020 adalah karena memanfaatkan waktu luang ketika layanan yang tidak dibuka akibat Covid19.

Selain untuk memanfaatkan waktu luang dan adanya sumber daya manusia yang berkenan melaksanakan stock opname, tujuan lain dari pelaksanaan stock opname yaitu untuk mengetahui validitas data aset koleksi. Validitas data aset koleksi sangat diperlukan karena untuk mendukung berjalannya kegiatan pengembangan koleksi misalnya, menyesuaikan aspek layanan, menjadi bahan pertimbangan saat melakukan pengadaan bahan pustaka dan sebagainya. Oleh karena itu, pada tahun 2020 baru dapat dilakukan dan dilaksanakan kegiatan stock opname.

Kegiatan stock opname pada bidang perpustakaan di Dinas Kearsipan dan Perpustakaan Kabupaten Kubu Raya dilakukan setelah mendapatkan persetujuan dari beberapa tahapan kepegawaian. Pertama pustakawan mengajukan ide kepada kepala seksi perpustakaan, kemudian kepala seksi mengajukan kepada kepala bidang perpustakaan. Sebenarnya setelah mendapatkan izin dari kepala bidang perpustakaan, stock opname sudah dapat dilaksanakan tetapi untuk mendukung kelancaran kegiatan maka kepala bidang mengajukan kepada kepala Dinas. Kepala Dinas memberikan persetujuan untuk dilaksanakannya kegiatan stock opname dengan syarat tidak mempengaruhi fokus sumber daya manusia perpustakaan dalam kegiatan yang telah dirancang dan dibuat pada program kerja tahunan

Kegiatan stock opname
berlangsung selama 6 bulan lamanya, dimulai sejak November 2020 sampai dengan Mei 2021. Sumber daya manusia yang melaksanakan kegiatan stock opname yaitu satu pustakawan, satu staf pelayanan perpustakaan, dua siswa magang dari Sekolah Menengah Kejuruan, dan dua mahasiswa magang dari Universitas. Pada awal pelaksanaan stock opname dilakukan hanya pustakawan dan staf pelayanan perpustakaan yang mengerjakannya. Pada awal Januari dibantu oleh siswa magang dari SMK, kemudian pada awal Maret dibantu oleh siswa magang dari Universitas, sehingga pelaksanaan stock 
opname di Perpustakaan Kubu Raya terbantu sehingga akhirnya selesai pada bulan Mei.

Dinas

$$
\text { Kearsipan }
$$

dan

Perpustakaan Kubu Raya tidak memiliki SOP (standar operational procedure) dalam pelaksanaan kegiatan stock opname secara khusus, tetapi selama melakukan kegiatan stock opname mengikuti prosedur pelaksanaan sesuai pengetahuan dan pengalaman dari pustakawan dan staf perpustakaan. Pustakawan dan staf pelayanan perpustakaan saling bertukar pikiran dalam pelaksanaan kegiatan stock opname ini, termasuk langkah-langkah pelaksanaan stock opname. Hal ini mempengaruhi langkah-langkah pelaksanaan yang sedikit berbeda dari pelaksanaan stock opname pada umumnya.

Tahapan kegiatan stock opname menurut Yulia (Universitas Ubudiyah Indonesia, 2015) yaitu terdiri dari 6 tahap.

a. Siapkan daftar buku

b. Daftar buku dicetak berdasarkan nomor klasifikasi sesuai urutan di rak buku.

c. Mencetak daftar buku yang sedang dipinjam, yang sedang rusak, dan yang sedang diperbaiki.

d. Mencocokkan daftar buku dengan koleksi di rak.

e. Beri tanda jika buku tersebut tidak ada selain dalam hitungan pinjaman, rusak, dalam perbaikan

f. Melakukan scanning buku.

Langkah-langkah pelaksanaan kegiatan stock opname yang dilakukan di Dinas Kearsipan dan Perpustakaan Kubu Raya, yaitu:

a. Meminta daftar koleksi perpustakaan dari daftar aset (inventarisasi aset)

Daftar aset adalah daftar yang didalamnya memuat semua barang/koleksi yang dimiliki oleh suatu organisasi. Khusus pada kegiatan stock opname maka yang diperlukan adalah daftar koleksi buku yang ada padaperpustakaan.

b. Membuat data formulir buku

$\begin{array}{ccr}\text { Data } & \text { formulir } & \text { buku } \\ \text { digunakan } & \text { untuk } & \text { mencatat } \\ \text { informasi } & \text { yang } & \text { diperlukan }\end{array}$
dalam kegiatan stock opname. Data formulir yang dibuat oleh pustakawan Perpustakaan Kubu Raya berpatokan pada informasi yang digunakan dalam kartu katalog karena setelah stock opname akan sekaligus pembuatan kartu katalog.

c. Mendata buku

Mendata buku di rak koleksi disesuaikan dengan data formulir yang telah dibuat sebelumnya oleh pustakawan. Pendataan buku dilakukan mulai dari koleksi yang sering dipinjam atau koleksi yang paling diminati oleh pemustaka.

d. Menyusun buku pada rak (shelving)

Buku yang sudah didata akan dilakukan penataan ulang pada rak koleksi yang biasa disebut shelving. Menurut Nashihuddin (2015) dalam melakukan shelving perlu memperhatikan landasan. Landasan pertama, penyusunan koleksi berdasarkan jenis koleksi; landasan kedua, koleksi disusun berdasarkan urutan nomor panggil dari yang terkecil hingga terbesar (sistem klasifikasi DDC); landasan ketiga, koleksi disusun berdasarkan huruf, nomor, atau kode selain sistem DDC yang tercantum pada nomor panggil buku; landasan keempat, koleksi disusun berdasarkan tiga huruf nama penulis; landasan kelima, koleksi disusun menurut 1 huruf dari judul buku; landasan keenam, koleksi disusun berdasarkan jilid, cetakan dan volume; landasan terakhir, koleksi disusun pada rak dari sebelah kiri ke kanan dalam satu rak atas ke bawah. 
e. Input data ke komputer pada ms.excel

Data buku yang pada awalnya dicatat pada kertas data formulir itu kemudian dipindahkan atau di input pada microsoft excel.

f. Mencocokkan data pada jajaran rak

Dalam kegiatan stock opname yang dilakukan oleh Perpustakaan Kubu Raya, langkah mencocokkan data yang didapat dengan koleksi pada jajaran rak ini memakan waktu yang cukup lama, karena butuh ketelitian dan kecermatan agar tidak terjadi kesalahan dalam mencocokkan data.

g. Input data dari ms.excel ke aplikasi perpustakaan

Hasil data dan koleksi pada jajaran rak yang telah dicocokkan dan di input pada microsoft excelkemudian langkah selanjutnya adalah input data dari microsoft excelke aplikasi perpustakaan SLiMS (Senayan Library Management System). Menurut Wince (2017) dengan adanya perkembangan teknologi pelaksanaan kegiatan stock opname dapat dipermudah yaitu menggunakan SLiMS.

h. Evaluasi

Evaluasi selalu dilakukan di akhir dari setiap kegiatan yang dilakukan oleh Dinas Kearsipan dan perpustakaan Kabupaten Kubu Raya. Evaluasi pada kegiatan stock opname dilakukan untuk mengukur tingkat keberhasilan dari stock opname. Keberhasilan yang dicapai dari kegiatan stock opname:

1. Pembuktian validitas data koleksi bahan pustaka.

2. Koleksi pada jajaraan rak tersusun secara rapi dan sesuai dengan nomor panggil buku.

3. Kartu katalog.

4. Database koleksi bahan pustaka yang update.
Kendala yang Dihadapi dalam Penerapan dan Pelaksanaan Kebijakan Stock Opname pada Dinas Kearsipan dan Perpustakaan Kabupaten Kubu Raya

Kendala diambil dari KBBI merupakan faktor atau keadaan yang membatasi, dapat menghalangi, mencegah tercapainya sasaran atau kekuatan pemaksaan pembatalan pelaksanaan.

Dinas Kearsipan dan Perpustakaan Kubu Raya memiliki hambatan untuk menerapkan kebijakan kegiatan stock opname. Kendala awal yang dihadapi adalah kurang dipahami tentang Standar Nasional Perpustakaan oleh sumber daya manusia perpustakaan. Sehingga semakin lama membuat sumber daya manusia perpustakaan yang lainnya juga belum ada yang berkenan untuk mengerjakan.

Dalam pelaksanaan kegiatan stock opnameterdapat beberapa hambatan yang dihadapi namun masih dapat diatasi oleh sumber daya manusia perpustakaan yang terlibat dalam pelaksanaan kegiatan stock opname ini. Walaupun dapat dihadapi, namun tetap menjadi penghambat keberhasilan pelaksanaan kegiatan tersebut. Adapun beberapa kendala yang dihadapi pada pelaksanaan stock opname perpustakaan Kubu Raya yaitu sebagai berikut:

a. Kurang diperhatikan pentingnya kegiatan stock opname

Stock opname bukanlah kegiatan inti atau utama dalam sebuah perpustakan, akan tetapi kegiatan stock opname sangat mempengaruhi berjalannya kegiatan perpustakaan yang lainnya. Oleh karena itu, apabila kegiatan stock opname tidak dilakukan akan menghambat berjalannya kegiatan stock opname.

b. Kurangya sumber daya manusia

$\begin{array}{crr}\text { Kegiatan } & \text { stock } & \text { opname } \\ \text { yang dilakukan pada } & \text { Dinas }\end{array}$


Kearsipan dan Perpustakaan Kubu Raya memerlukan sumber daya manusia untuk melakukan kegiatan stock opname.

c. Waktu pelaksanaan yang tidak konsisten

$$
\text { Dinas kearsipan dan }
$$

Perpustakaan Kubu Raya melaksanaan kegiatan stock opname cukup lama yakni 6 bulan.

d. Tidak ada dana

Dinas Kearsipan dan Perpustakaan Kubu Raya tidak memiliki dana yang dialokasikan untuk kegiatan stock opname yang dilaksanakan kali ini.

\section{SIMPULAN DAN SARAN}

\section{Simpulan}

Berdasarkan hasil penelitia dapat disimpulkan bahwa Dinas Kearsipan dan Perpustakaan Kabupaten Kubu Raya tidak memiliki kebijakan tertulis mengenai pelaksanaan kegiatan stock opname pada koleksi perpustakaan. Kegiatan stock opname belum pernah dilakukan sejak berdirinya perpustakan yaitu 2008 dan baru dilakukan pertama kali pada tahun 2020. Kegiatan ini dilakukan karena ide dari pustakawan untuk memanfaatkan waktu luang, yakni tutup layanan perpustakaan akibat covid19.Dalam melaksanakan kegiatan stock opname terdapat beberapa kendala yang dialami yaitu kurangnya sumber daya manusia perpustakaan, tidak ada Dana, waktu pelaksanaan yang tidak konsisten, dan kurang diperhatikan pentingnya stock opname.

\section{Saran}

Dari hasil penelitian yang peneliti dapatkan, maka ada beberapa hal yang dapat disarankan yaitu diharapkan untuk membuat kebijakan kegiatan stock opname, agar kegiatannya dapat dilakukan dengan konsisten memasukkan kegiatan stock opname dalam program kerja tahunan, agar dalam melaksanakan kegiatan stock opname berikutnya semua persiapan telah matang, dengan persiapan yang lebih baik maka dapat dipastikan kegiatan stock opname berikutnya tidak akan ditemukan kendala-kendala seperti yang dialami saat ini.

\section{DAFTAR RUJUKAN}

Badan Pengembangan dan Pembinaan Bahasa, Kementerian Pendidikan, Kebudayaan, Riset dan Teknologi Republik Indonesia. (2016). (KBBI Daring). Diakses dari https://kbbi.kemdikbud.go.id/entri/k e bijakan 25 Mei 2021

Badan Pengembangan dan Pembinaan Bahasa, Kementerian Pendidikan, Kebudayaan, Riset dan Teknologi Republik Indonesia. (2016). (KBBI Daring). Diakses dari https://kbbi.kemdikbud.go.id/entri/k e ndala 2 Oktober 2021

Emzir, S. (2011). Metode Penelitian Kualitatif Analisis Data. Jakarta: Rajawali Pers.

Nashihuddin, W. (2015). Panduan penjajaran koleksi perpustakaan (Shelving). Jakarta: Pusat Dokumentasi dan Informasi Ilmiah. Diakses dari https://library.uui.ac.id/upload/daab u $\quad$ ku_panduan_stock_opname.pdf 27 September 2021

Perpustakaan Nasional RI. (2019). Standar Nasional Perpustakaan Provinsi, Kabupaten/Kota, Kecamatan, Desa/Kelurahan. Jakarta: Perpustakaan Nasional RI. Diakses dari https://dispusip.jembranakab.go.id/a ssets/pedoman/026db291884d52d05 7f91df7ff864c34.pdf 30 Agustus 2021

Putra, Dimas Andika. (2015). Implementasi Stock Opname di 
Perpustakaan UIN Malang. Skripsi. Malang: Fakultas Sastra Indonesia Prodi Perpustakaan. http://karya-

ilmiah.um.ac.id/index.php/Perpust akaan/article/view/44572 diunduh, 5 April 2021.

Rodin, R. (2018). Implementasi Fungsi Manajemen dalam Pengelolaan Perpustakaan. Yogyakarta: Suluh Media.

Saleh, A.R. (2011). Manajemen Perpustakaan. Jakarta: Universitas Terbuka.

Saleh, A.R. dan Komalasari, R. (2011). Manajemen Perpustakaan. Jakarta: Universitas Terbuka.

Subagio, Ilham. (2019). Stock Opname Koleksi Perpustakaan SDN 34 Pontianak. Pontianak: Universitas Tanjungpura.

Sugiyono. (2018). Metode Penelitian Kualitatif. Bandung: Alfabeta.

Sugiyono. (2019). Metode Penelitian Kuantitatif Kuantitatif dan $R \& D$. Bandung: Alfabeta.
Universitas Ubudiyah Indonesia. (2015). Panduan Stock Opname Perpustakaan Ubudiyah Binti A. Wahab. Banda Aceh. https://library.uui.ac.id/upload/daabuku_panduan_stock_opname.pdf diunduh, 25 September 2021.

Wince, E. (2017). Kajian Pentingnya Stock Opname Dalam Pengembangan Koleksi Perpustakaan. Jurnal Ilmu Perpustakaan dan Informasi. Curup: Perpustakaan STAIN Curup. Diakses dari http://journal.iaincurup.ac.id/index.p $\mathrm{hp} / \mathrm{TI} /$ article/view/205/93 5 April 2021

Yulia, Y dan Sujana, J.G. (2011). Pengembangan Koleksi. Jakarta: Universitas Terbuka 